\title{
Possible Neuroprotective Properties of Flunarizine Infused after Asphyxia in Fetal Lambs Are Not Explained by Effects on Cerebral Blood Flow or Systemic Blood Pressure
}

\author{
HARMEN H. DE HAAN, JOS L. H. VAN REEMPTS, MARCEL BORGERS, JELTE DE HAAN, \\ JOHAN S. H. VLES, AND TOM H. M. HASAART \\ Departments of Obstetrics and Gynecology /H.H.d.H., J.d.H., T.H.M.H./ and Child Ne'urology [J.S.H.V.J. \\ University Hospital, Maastricht, The Netherlands, and the Department of Life Sciences, Janssen Research \\ Foundation, B-2340 Beerse, Belgium [J.L.H.V.R., M.B.]
}

\begin{abstract}
Neuroprotective properties of the calcium channel blocker flunarizine have been reported after hypoxic-ischemic insults in immature, infant, and adult rats. However, its effect on fetal regional cerebral blood flow (rCBF) and systemic blood pressure after severe asphyxia is not known. In 15 fetal lambs ( 3 to $5 \mathrm{~d}$ after surgery; gestational age at the experiment, $123.2 \pm 2.5 \mathrm{~d}$ ), arterial oxygen content was progressively reduced to $30 \%$ by restriction of uterine blood flow with an inflatable balloon occluder around the maternal common internal iliac artery. The $\mathrm{rCBF}$ was measured with radioactive microspheres at baseline condition, after $1 \mathrm{~h}$ of severe asphyxia, and at 30 and $120 \mathrm{~min}$ in the recovery phase. Immediately after the end of the occlusion period, fetuses randomly received either flunarizine or its solvent $(0.5 \mathrm{mg} / \mathrm{kg}$ estimated fetal weight). No differences in $\mathrm{rCBF}$ changes between groups were observed during and after asphyxia. Changes in arterial blood pressure or fetal heart rate due to flunarizine could not be demonstrated either. Only five fetuses (33\%) survived this degree of asphyxia longer than $24 \mathrm{~h}$ : four of the flunarizine-treated group and one of the control group. It is unlikely that this possible protective property of the drug is caused by its influence on rCBF, arterial blood pressure, or fetal heart rate in the phase immediately after asphyxia. (Pediatr Res 34: 379-384, 1993)
\end{abstract}

Abbreviations

$\mathrm{rCBF}$, regional cerebral blood flow

FHR, fetal heart rate

$\mathrm{Pa}$, arterial blood pressure

$\mathrm{Pv}$, venous blood pressure

$\left[\mathrm{O}_{2}\right] \mathrm{a}$, arterial oxygen content

$\mathrm{PaCO}_{2}$, arterial carbon dioxide tension

post-1, postasphyxia 1 ; time $=90 \mathrm{~min}$

post-2, postasphyxia 2 ; time $=180 \mathrm{~min}$

Brain damage due to perinatal asphyxia is a clinically relevant target of research (1). In this respect, important results have been obtained in neonatal and in adult rats in which calcium channel blockers have shown structural and functional brain protective

Received December 6, 1991; accepted April 8, 1993.

Correspondence: Harmen H. de Haan, M.D., Department of Obstetrics and Gynecology, University Hospital, P.O. Box 5800, 6202 AZ Maastricht, The Netherlands. properties in various experimental setups. Newborn and infant rats, pretreated with the class IV calcium channel blocker flunarizine (2) and submitted to hypoxic-ischemic insults, had less brain damage compared with nontreated controls (3-5). Flunarizine treatment after induction of cortical damage in adult rats improved brain function and reduced infarct size (6). Regarding blood flow, flunarizine decreased the rate of the stimulated calcium influx into vascular smooth muscle cells of the rat tail and rabbit ear and, therefore, inhibited the peripheral vasoconstriction and vasospasm evoked by tissue anoxia (7). After 10 min of complete ischemia in the adult dog, the brain protective effect of nimodipine, a class II calcium channel blocker (2), was attributed to a nearly doubled cerebral blood flow (8).

The fetus reacts to hypoxia with an increase in cerebral blood flow to maintain cerebral oxygen delivery (9). The effect of flunarizine on fetal rCBF and on fetal cardiovascular parameters is not known. To mimic treatment after fetal pathophysiology, we chose to administer flunarizine after a period of severe asphyxia. The lack of oxygen results in energy failure, which leads to impeded ATP-dependent $\mathrm{Na}^{+} / \mathrm{K}^{+}$-transport. The ensuing decrease in membrane potential opens voltage-dependent calcium gates. Additionally, the decrease of the transmembrane sodium gradient diminishes outward calcium transport. Intracellular influx of calcium is an important factor in the mechanism of cell death (10). The intracellular calcium concentration is normally maintained near $0.1 \mu \mathrm{M}$, which is 10000 -fold less than the extracellular calcium concentration (11). Calcium shifts occurring with ischemic-anoxic energy failure are responsible for massive calcium overload in neurons, leading to activation of phospholipases. This results in accumulation of FFA and in swelling and edema of neurons. The latter further compromises oxygen supply (12).

Flunarizine, a possible neuroprotective drug, was studied in the chronic fetal sheep model, which allows accurate measurements of $\mathrm{rCBF}, \mathrm{FHR}, \mathrm{Pa}$, and $\mathrm{Pv}$ during and after severe fetal asphyxia. The hypothesis tested was that flunarizine improves $\mathrm{rCBF}$ in the phase immediately after asphyxia and that this may lead to improved fetal outcome after severe asphyxia.

\section{MATERIALS AND METHODS}

Surgery. Surgery was performed in 15 pregnant Dutch Texel sheep. Gestational age varied between 115 and $124 \mathrm{~d}$ (mean \pm $\mathrm{SD}=119.2 \pm 2.3 \mathrm{~d}$, term $=147 \mathrm{~d}$ ).

General anesthesia was induced with pentobarbital i.v. and maintained with $1 \%$ halothane in a $2: 1$ mixture of nitrous oxide and oxygen. Before surgery, the ewes received $1 \mathrm{~g}$ of ampicillin i.v. Instrumentation was performed as described previously (13). 
Briefly, a paramedian abdominal incision was made, and an inflatable balloon occluder was placed around the maternal common internal iliac artery. Catheters were inserted in the fetal axillary and femoral artery, and the tips were advanced to the level of the brachiocephalic trunk and descending aorta, respectively. In addition, fetal catheters were placed in the femoral vein, the tip was advanced into the inferior vena cava, and in the amniotic cavity. Electrodes were placed to record the fetal ECG and electrocorticogram, and a catheter in the fourth ventricle allowed sampling of cerebrospinal fluid. Catheters and wires were exteriorized to the ewe's flank.

Ewes were housed in individual cages, had free access to food and water, and were allowed to recover from surgery for at least $3 \mathrm{~d}$ before experiments were started. A continuous slow infusion $(1 \mathrm{~mL} / \mathrm{h})$ of heparine in saline $(10 \mathrm{U} / \mathrm{mL})$ was used to maintain patency of fetal arterial and venous catheters. Guidelines for care and use of animals approved by the local Animal Medical Ethics Committee were followed.

Measurements. rCBF was measured by radioactive microspheres with a diameter of $15 \mu \mathrm{m}$. At random, one of four available microspheres $\left({ }^{141} \mathrm{Ce},{ }^{103} \mathrm{Ru},{ }^{95} \mathrm{Nb}\right.$, and $\left.{ }^{113} \mathrm{Sn}\right)$ was injected. Aggregation was prevented by adding $0.05 \%$ Tween 80 to the medium. After homogenization in an ultrasonic $39^{\circ} \mathrm{C}$ water bath (Bransonic 5200, Soest, The Netherlands) for $20 \mathrm{~min}$, approximately $0.5 \times 10^{6}$ microspheres were stirred on a vortex agitator and infused gradually over a period of $1 \mathrm{~min}$ into the inferior vena cava (14). Reference sampling $(1.80 \mathrm{~mL} / \mathrm{min})$ was started from the brachiocephalic arch, $30 \mathrm{~s}$ before infusion, continued during infusion, and stopped $1 \mathrm{~min}$ after infusion, using a variable speed peristaltic pump (Harvard Apparatus 1210, Edenbridge, England).

$\mathrm{Pa}, \mathrm{Pv}$, and amniotic pressure were determined with the zero point at the level of the ewe's spine. These signals, together with the FHR derived from the pulsatile signal of the femoral artery, were led to a bioelectric amplifier (Hewlett-Packard 8800 series, Andover, MA), displayed on a monitor, recorded on an eightchannel strip chart recorder, stored on magnetic tape, and digitized and analyzed with a computer.

Immediately after microsphere injection, $2 \mathrm{~mL}$ of blood were withdrawn from the axillary artery and centrifuged $(3 \mathrm{~min}$ at $13000 \mathrm{rpm})$. Serum was frozen in liquid nitrogen and stored at $-73^{\circ} \mathrm{C}$ to determine lactate concentrations. Blood gas values and $\mathrm{pH}$ from the fetal aortic arch were measured with an automated analyzer (AVL, Radiometer, Copenhagen, Denmark) and corrected for $39^{\circ} \mathrm{C}$. Hb saturation was measured with an hemoximeter (OSM2 Hemoximeter, Radiometer). The $\left[\mathrm{O}_{2}\right] \mathrm{a}$ was calculated as follows:

\section{$\left[\mathrm{O}_{2}\right] \mathrm{a}(\mathrm{mM})=\mathrm{Hb}$ concentration $(\mathrm{mmol} / \mathrm{L})$}

$\times$ Hb oxygen saturation $(\% / 100)$

Experiments. Gestational age at the beginning of experiments varied between 119 and $129 \mathrm{~d}$ (mean $\pm S D=123.2 \pm 2.5 \mathrm{~d}$ ). Baseline values were obtained during a control period of $2 \mathrm{~h}$. Fetal acid-base state was analyzed every $15 \mathrm{~min}$.

Figure 1 shows the experimental protocol. After measurement of $\mathrm{rCBF}$ in the baseline control period, severe asphyxia was induced by gradual reduction of maternal uterine blood flow by stepwise inflation of the balloon occluder around the common internal iliac artery. To maintain the fetus in a stable hemodynamic condition, uterine blood flow was gradually reduced over a period of 90 to $120 \mathrm{~min}$ until fetal $\left[\mathrm{O}_{2}\right]$ a was reduced to approximately $30 \%$ of the baseline value. This latter asphyxic condition was maintained for $1 \mathrm{~h}$. At the end of this period, at time $=60 \mathrm{~min}, \mathrm{rCBF}$ was remeasured (asterisks in Fig. 1). Uterine blood flow obstruction was then discontinued by emptying the balloon occluder. At this moment the animals were randomized and treatment was started; seven fetuses received flunarizine $(0.5$ $\mathrm{mg} / \mathrm{kg}$ estimated fetal weight), whereas the control group consisted of eight fetuses receiving the solvent, $10 \% 5-\mathrm{OH}-$ propyl- $\beta$ cyclodextrine. To avoid possible side effects such as systemic hypotension and tachycardia, we administered flunarizine or the solvent in two dosages over a period of $1 \mathrm{~h}$ infused in the axillary artery. The first dosage was given immediately after the period of severe asphyxia, the second infusion started at time $=180$ min. In the first animals, fetal serum levels of flunarizine were determined during various moments in the experiment. The $\mathrm{rCBF}$ was again determined at time $=90 \mathrm{~min}$ (post-1, which is during the first treatment) and at time $=180 \mathrm{~min}$ (post-2, just before the second treatment).

The experiment was ended when either the fetus had died or, in case of fetal survival, after $3 \mathrm{~d}$. Then the ewe was killed by an overdose of pentobarbital, the fetus was removed and weighed, and correct catheter placement was confirmed. The fetal cerebrum was dissected into eight different anatomical entities: frontal cortex, parietal cortex, temporal cortex, striatum, hippocampus, cerebellum, thalamus, and medulla oblongata.

Calculations and data analysis. Different tissue samples were weighed $( \pm 1 \mathrm{~g})$, put into test tubes, and preserved in fixative containing a $2 \%$ formaldehyde and $2.5 \%$ glutaraldehyde solution. All four isotopes were counted simultaneously. Radioactivity in the eight cerebral entities and in the reference samples was measured with an automatic gamma counter and sample changer system (analyzer model 45, Molsgaard Medical, Horsholm, Denmark). The rCBF was calculated with an ND680 programmable analyzer/computer system (Nuclear Data GmbH, Frankfurt, Germany).

FHR, $\mathrm{Pa}$, and $\mathrm{Pv}$, corrected for amniotic pressure, were averaged over 10 -s periods using a computer program. Five of these epochs were averaged to calculate mean values. Data obtained at several moments in the experiment within one group were compared with a Friedman two-way analysis of variance, with time as the repeated measure. Differences between the flunarizine-treated group and the control group were tested with the two-tailed Mann-Whitney $U$ test. A $p$ value $<0.05$ was taken to represent statistical significance.

\section{RESULTS}

Infusion of flunarizine resulted in fetal serum levels well within the therapeutic range, i.e. $>200 \mu \mathrm{g}$ flunarizine/L serum (15).

Table I summarizes the fetal acid-base state at the four moments of blood flow measurement. $\left[\mathrm{O}_{2}\right] \mathrm{a}(\mathrm{mM}), \mathrm{pH}, \mathrm{PCO}_{2}(\mathrm{kPa})$, base excess $(\mathrm{mM})$, and serum lactate concentration $(\mathrm{mM})$ are expressed at baseline condition, at the end of the 1 -h period of severe asphyxia (time $=60 \mathrm{~min}$ ), at post -1 , and at post -2 for both the flunarizine-treated group and the control group. Uterine blood flow restriction resulted in a reduction of the $\left[\mathrm{O}_{2}\right] \mathrm{a}$ to about $30 \%$ of baseline level. After $1 \mathrm{~h}$ of severe asphyxia, the mean $\mathrm{pH}$ had decreased to 7.08 and 7.09 in the flunarizinetreated group and the control group, respectively. In the recovery phase, the mean oxygen saturation did not return to baseline values. This resulted in an $\left[\mathrm{O}_{2}\right]$ a significantly below baseline levels at post-1 and post-2, whereas $\mathrm{pH}$ and base excess increased only slightly. Serum lactate concentrations at post- 1 and post-2 are in the same range as in the period of severe asphyxia.

Table 2 shows the weight-specific $\mathrm{rCBF}$ in $\mathrm{mL} / \mathrm{min} \times 100 \mathrm{~g}$ during baseline, asphyxia, and postasphyxia for eight cerebral areas. The amount of microspheres used was sufficient, as all of the dissected tissues and samples contained more than 400 microspheres (16). Adequate mixing was proven by the absence of significant differences between the amount of microspheres in left and right kidney. Baseline levels of blood flow in phylogenetic older structures as cerebellum, thalamus, and especially medulla oblongata were higher compared with younger structures as cortices (Mann-Whitney $U$ test, $p<0.05$ ). Blood flow to nearly all parts of the brain more than doubled in response to asphyxia. At post-1, during the first treatment, mean $\mathrm{rCBF}$ decreased compared with asphyxia but had not yet returned to baseline values. At post-2, rCBF in the flunarizine-treated group returned to baseline values, whereas $\mathrm{rCBF}$ in the control group remained 


$\underset{c}{\text { baseline }} \stackrel{\text { Occlusion }}{\longrightarrow}$

Fig. 1. Experimental protocol. Asterisks indicate rCBF measurement. The last two measurements correspond with post-1 and post-2 in the text. Treatment consisted of either flunarizine or its solvent.

Table 1. Fetal acid-base state*

\begin{tabular}{lcccc}
\hline & Baseline & Asphyxia & Post-1 & Post-2 \\
\hline Flunarizine group & & & & \\
{$\left[\mathrm{O}_{2}\right] \mathrm{a}(\mathrm{mM})$} & $3.86 \pm 0.44$ & $1.13 \pm 0.24 \dagger$ & $2.64 \pm 0.46 \dagger$ & $2.48 \pm 0.73 \dagger$ \\
$\mathrm{pH}$ & $7.37 \pm 0.02$ & $7.08 \pm 0.01 \dagger$ & $7.13 \pm 0.02 \dagger$ & $7.27 \pm 0.04 \dagger$ \\
$\mathrm{PCO}_{2}(\mathrm{kPa})$ & $4.79 \pm 0.28$ & $6.78 \pm 0.49 \dagger$ & $5.52 \pm 0.26 \dagger$ & $5.75 \pm 0.41$ \\
$\mathrm{Base}$ excess $(\mathrm{mM})$ & $-3.5 \pm 0.9$ & $-15.4 \pm 1.1 \dagger$ & $-14.8 \pm 1.4 \dagger$ & $-9.7 \pm 2.4 \dagger$ \\
Lactate $(\mathrm{mM})$ & $1.5 \pm 0.3$ & $11.2 \pm 2.6 \dagger$ & $9.4 \pm 0.2 \dagger$ & $10.8 \pm 2.5 \dagger$ \\
$\mathrm{Control}$ group & & & \\
{$\left[\mathrm{O}_{2}\right] \mathrm{m}(\mathrm{mM})$} & $3.38 \pm 0.34$ & $1.14 \pm 0.11 \dagger$ & $1.86 \pm 0.29 \dagger$ & $1.56 \pm 0.32 \dagger$ \\
$\mathrm{pH}$ & $7.36 \pm 0.03$ & $7.09 \pm 0.03 \dagger$ & $7.12 \pm 0.03 \dagger$ & $7.15 \pm 0.07 \dagger$ \\
$\mathrm{PCO}(\mathrm{kPa})$ & $4.61 \pm 0.24$ & $5.96 \pm 0.45 \dagger$ & $4.82 \pm 0.23$ & $5.71 \pm 0.70$ \\
Base excess $(\mathrm{mM})$ & $-3.5 \pm 1.0$ & $-17.0 \pm 0.7 \dagger$ & $-16.8 \pm 1.3 \dagger$ & $-13.3 \pm 2.6 \dagger$ \\
Lactate $(\mathrm{mM})$ & $1.8 \pm 0.2$ & $9.6 \pm 0.8 \dagger$ & $9.0 \pm 0.4 \dagger$ & $11.9 \pm 2.5 \dagger$ \\
\hline
\end{tabular}

* Values are expressed as mean \pm SEM. Asphyxia is at time $=60 \mathrm{~min}$. post -1 is at time $=90 \mathrm{~min}$, and post -2 is at time $=180 \mathrm{~min}$. $n=8$ for control group and $n=7$ for flunarizine group, except at post-2 when $n=7$ and $n=6$, respectively.

$\dagger p<0.05$ (asphyxia, post-1, or post-2 is baseline; Friedman two-way analysis of variance).

Table 2. $r C B F^{*}$

\begin{tabular}{lclll}
\hline & Baseline & Asphyxia & Post-1 & Post-2 \\
\hline Funarizine group & & & & \\
Frontal cortex & $110 \pm 32$ & $225 \pm 34 \dagger 184 \pm 50$ & $124 \pm 20$ \\
Parietal cortex & $117 \pm 28$ & $217 \pm 43 \dagger 187 \pm 62$ & $121 \pm 19$ \\
Temporal cortex & $126 \pm 39$ & $203 \pm 44 \dagger 165 \pm 57$ & $122 \pm 23$ \\
Striatum & $138 \pm 32$ & $265 \pm 51 \dagger 190 \pm 17$ & $139 \pm 21$ \\
Yippocampus & $142 \pm 42$ & $247 \pm 51 \dagger 161 \pm 59$ & $149 \pm 23$ \\
Crebellum & $192 \pm 71$ & $350 \pm 47 \dagger 293 \pm 68$ & $201 \pm 33 \ddagger$ \\
Thalamus & $210 \pm 61$ & $452 \pm 80 \dagger 329 \pm 85$ & $229 \pm 39$ \\
Medulla oblongata & $265 \pm 102$ & $558 \pm 76 \dagger 385 \pm 123$ & $292 \pm 70$ \\
Control group & & & & \\
Frontal cortex & $114 \pm 25$ & $275 \pm 50 \dagger 188 \pm 34 \dagger$ & $183 \pm 18 \dagger$ \\
Parietal cortex & $101 \pm 20$ & $260 \pm 46 \dagger 179 \pm 24 \dagger$ & $164 \pm 14 \dagger$ \\
Temporal cortex & $89 \pm 18$ & $221 \pm 41 \dagger 151 \pm 27$ & $152 \pm 15 \dagger$ \\
Striatum & $148 \pm 30$ & $341 \pm 77 \dagger 223 \pm 27$ & $211 \pm 29 \dagger$ \\
Hippocampus & $120 \pm 21$ & $289 \pm 65 \dagger 173 \pm 37$ & $200 \pm 21 \dagger$ \\
Cerebellum & $161 \pm 32$ & $422 \pm 64 \dagger 325 \pm 43$ & $307 \pm 22 \dagger \dagger$ \\
Thalamus & $201 \pm 29$ & $501 \pm 89 \dagger 320 \pm 48$ & $334 \pm 23 \dagger$ \\
Medulla oblongata & $196 \pm 41$ & $578 \pm 92 \dagger 361 \pm 53$ & $377 \pm 39$ \\
\hline
\end{tabular}

* Values are expressed as mean $\pm \mathrm{SEM}(\mathrm{mL} / \mathrm{min} \times 100 \mathrm{~g})$. Asphyxia is at time $=60 \mathrm{~min}$, post -1 is at time $=90 \mathrm{~min}$, and post -2 is at time $=$ 180 min. $n=8$ for control group and $n=7$ for flunarizine group, except at post -2 when $n=7$ and $n=6$, respectively.

$\dagger p<0.05$ (asphyxia, post-1, or post-2 vs baseline; Friedman two-way analysis of variance).

$\ddagger p<0.05$ (flunarizine-treated group is control group: two-tailed Mann-Whitney $U$ test)

significantly higher compared with baseline. However, no differences were demonstrated between both groups, except for cerebellar flow, which was higher in the control group at post-2.

Fetal cardiovascular parameters at the four moments of rCBF measurement are summarized in Table 3 . During the experiment
Table 3. Fetal cardiovascular parameters*

\begin{tabular}{lrrrr}
\hline & Baseline & Asphyxia & Post-1 & \multicolumn{1}{c}{ Post-2 } \\
\hline Flunarizine group & & & & \\
FHR (beats/min) & $172 \pm 7$ & $194 \pm 22 \dagger$ & $210 \pm 13 \dagger$ & $194 \pm 17 \dagger$ \\
Pa (mm Hg) & $46.2 \pm 2.2$ & $45.5 \pm 3.7$ & $44.7 \pm 3.4$ & $42.5 \pm 4.3$ \\
Pv (mm Hg) & $6.2 \pm 1.6$ & $5.5 \pm 1.5$ & $6.0 \pm 1.6$ & $5.9 \pm 1.4$ \\
Pa-Pv (mm Hg) & $45.0 \pm 5.0$ & $39.1 \pm 3.9$ & $41.0 \pm 4.1$ & $35.7 \pm 4.8$ \\
Control group & & & & \\
FHR (beats/min) & $180 \pm 12$ & $221 \pm 13 \dagger$ & $212 \pm 12 \dagger$ & $206 \pm 31 \dagger$ \\
Pa (mm Hg) & $51.6 \pm 2.5$ & $48.2 \pm 3.8$ & $48.2 \pm 3.7$ & $47.3 \pm 3.4$ \\
Pv (mm Hg) & $4.5 \pm 0.9$ & $4.8 \pm 3.8$ & $7.5 \pm 1.0$ & $6.7 \pm 1.1$ \\
Pa-Pv (mm Hg) & $47.2 \pm 3.4$ & $43.5 \pm 3.6$ & $40.7 \pm 3.4$ & $42.3 \pm 4.4$ \\
\hline
\end{tabular}

*Values are expressed as mean \pm SEM. Asphyxia is at time $=60 \mathrm{~min}$. post-1 is at time $=90 \mathrm{~min}$, and post-2 is at time $=180 \mathrm{~min} . n=8$ for control group and $n=7$ for the flunarizine group, except at post-2 when $n=7$ and $n=6$, respectively.

$\dagger p<0.05$ (asphyxia, post-1, or post-2 is baseline: Friedman two-way analysis of variance).

FHR increased, whereas $\mathrm{Pa}$ and $\mathrm{Pv}$ did not change. Perfusion pressure (Pa-Pv) in individual animals was calculated and did not change during the experiment. No differences between groups could be demonstrated.

In Figure 2 the time course of FHR, $\mathrm{Pa},\left[\mathrm{O}_{2}\right] \mathrm{a}$, and $\mathrm{pH}$ for both experimental groups is depicted. The time scale on the ordinate is the same as in Figure 1. No significant differences between the groups in any of the four parameters were demonstrated (two-tailed Mann-Whitney $U$ test).

The entire experiment resulted in a mean fetal blood loss of $28.5 \mathrm{~mL}$. This consisted of approximately $25 \times 0.1 \mathrm{~mL}$ for the various determinations of the fetal acid-base state, added to $4 \times$ $2.5 \mathrm{~min} \times 1.80 \mathrm{~mL} / \mathrm{min}$ for $\mathrm{rCBF}$ measurements, added to $4 \times$ $2.0 \mathrm{~mL}$ for fetal serum analysis.

Fetal survival after severe asphyxia was poor: 10 animals (seven 

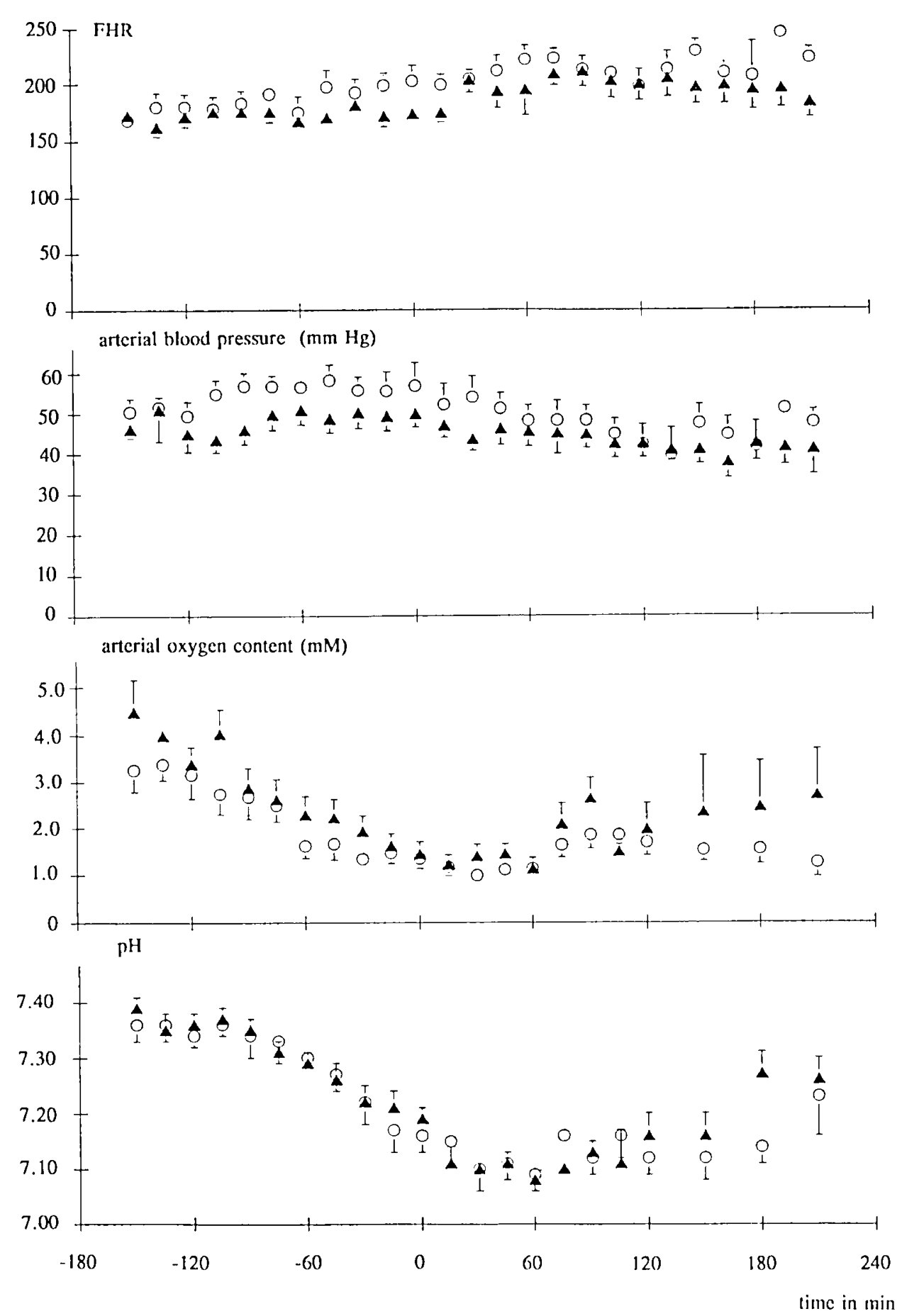

Fig. 2. Time course of FHR, $\mathrm{Pa},\left[\mathrm{O}_{2}\right] \mathrm{a}$, and $\mathrm{pH}$ (mean $\pm \mathrm{SEM}$ ). Time -180 to $-120 \mathrm{~min}=$ baseline period; time -120 to 0 min $=$ progressive reduction of uterine blood flow; time 0 to $60 \mathrm{~min}=1 \mathrm{~h}$ period of severe asphyxia; time 60 to $240 \mathrm{~min}=$ recovery period. Filled triangles represent flunarizine-treated group; open circles represent control group.

of the control group versus three of the flunarizine-treated group) died during the first $24 \mathrm{~h}$. In each group one animal survived a very short period, reducing the number of animals to $n=7$ and $n=6$ at post- 2 for the control group and the flunarizine-treated group, respectively. In both groups one fetal lamb died between 1 and $3 \mathrm{~d}$. The last three fetuses, all of the flunarizine-treated group, survived and were killed after $3 \mathrm{~d}$.

\section{DISCUSSION}

To rationalize the use of calcium channel blockers in the treatment of brain ischemia-anoxia, two major theories are de- veloped. The first theory is the augmentation of cerebral oxygen delivery. The mechanisms considered responsible are inhibition of calcium influx into vascular smooth muscle cells, thus relieving the vascular spasm originating from anoxia (7). Another mechanism involved is the inhibition of calcium influx into red blood cells, causing the erythrocyte deformability to remain intact (17). Studies on the impact of calcium channel blockers on rCBF and neurologic recovery after cerebral ischemia in adult dogs have yielded conflicting outcomes. Results varied from considerable benefits to total absence of improvement $(8,18$, 19). The second theory is that calcium channel blockers would directly reduce calcium entry into neurons, thereby enhancing 
resistance to injury. Flunarizine proved to be a potent blocker of low-threshold calcium channels (20). Maintaining low intracellular concentrations of calcium is an important modality in the prevention of cell death $(10,12)$. Van Reempts et al. (21) observed a reduced infarct size after photochemically induced thrombosis in spontaneously hypertensive rats and postulated on the basis of histologic findings that flunarizine might contribute to preservation of the integrity of endothelial cell membranes (reduction of platelet adhesion and vasogenic edema formation), of neuronal cell membranes (inhibition of calcium overload), and of glial cell membranes (prevention of cytotoxic edema formation). More recently, flunarizine enhanced neuronal survival in lumbar sensory ganglia from newborn rats after axotomy (22). The researchers suggested that this effect was caused by unknown intracellular acting mechanisms, distinct from blockade of voltage-dependent calcium channels.

Before considering the use of calcium channel blockers in the treatment of perinatal asphyxia, extensive animal research on the effects of these drugs on fetal brain circulation, metabolism, and function are needed (1). The present study not only focuses on the effect of flunarizine on the fetal rCBF after asphyxia but also analyzes the effect on FHR and fetal systemic blood pressure. Flunarizine is a highly lipophylic substance, easily crossing the blood-brain barrier. In humans it is used to treat neurologic disorders varying from migraine and vertigo to epilepsy (16). To mimic treatment in a clinical pathologic condition, we chose to start the infusion of flunarizine after a profound and prolonged period of asphyxia.

Oxygen delivery to the brain depends on both the $\left[\mathrm{O}_{2}\right] \mathrm{a}$ and the rCBF. The rCBF varies with gestational age. Baseline values in the present study correspond with those reported by others $(23,24)$. No differences in rCBF changes between both groups, either in the baseline period or asphyxia period or in the phase immediately after severe asphyxia during which flunarizine was administered, were observed. The $\left[\mathrm{O}_{2}\right] \mathrm{a}$ in both groups was comparable during baseline and asphyxia. Also, in the postasphyxic phase, the $\left[\mathrm{O}_{2}\right]$ a between groups was not statistically different. It can only be speculated that the nonsignificant slightly higher $\left[\mathrm{O}_{2}\right] \mathrm{a}$ in the flunarizine-treated group might be caused by better brain functioning, improved myocardial performance, and placental perfusion, or by coincidence. At post-2, rCBF in the control group is still elevated compared with baseline, whereas $\mathrm{rCBF}$ has normalized in the flunarizine-treated group. Therefore, the nat result of oxygen delivery is the same in both groups. The increased $\mathrm{rCBF}$ in animals suffering from hypoxia or asphyxia is in agrem: nt with literature (9).

Rediction of maternal uterine blood flow with a balloon occluder around the common internal iliac artery resulted in severe asphyxia in all animals. An immediate effect of occlusion was a iransient bradycardia with arterial hypertension. These cardiovascilar parameters soon stabilized, resulting after $1 \mathrm{~h}$ of severe asphyxia in tachycardia and normal blood pressure in both groups. This is in agreement with data from others (24). The change from bradycardia to tachycardia and hypertension to normotension might be secondary to a sustained release of catecholamines (25), in combination with hypercapnia, which reduces vagal inhibition and thereby enhances sympathetic stimulation of the FHR (26). The degree and duration of asphyxia have their influence on cardiovascular reaction patterns $(27,28)$. One possible explanation for the final decompensation after severe aspinyxia is hypoxic myocardial failure, which is accompanied by an elevation in central venous pressure and the development of hypotension (28). Cardiovascular reaction patterns were not inlluenced by the infusion of flunarizine, as can be seen from the FHR and Pa data in Figure 2. When asphyxia becomes too severe, oxygen delivery to vital organs can no longer be maintained (29). The ensuing anaerobic metabolism increases the amount of serum lactate in the fetus (28). In the present study, lactate concentrations increased to approximately $10 \mathrm{mM}$ during asphyxia and remained at this level at least $2 \mathrm{~h}$ after the period of severe asphyxia. Although the $\left[\mathrm{O}_{2}\right]$ a failed to recover to baseline values and the acid-base state did not normalize, fetal cardiovascular function in the first $3 \mathrm{~h}$ after asphyxia appeared to be adequate, as is suggested by a normal $\mathrm{Pa}$ and $\mathrm{Pv}$. Perfusion pressure ( $\mathrm{Pa}-\mathrm{Pv})$ also remained unaltered during the experiment in both groups.

The mean fetal blood loss of approximately $28.5 \mathrm{~mL}$ per animal in the present study did not result in a decrease in fetal $\mathrm{Hb}$ levels or even in fetal anemia. This is in accordance with the study of Brace and Cheung (30) who removed an average of $120.3 \pm 5.1 \mathrm{~mL}$ of blood ( $30.8 \%$ of the initial blood volume) in a period of $2 \mathrm{~h}$ in fetal lambs. Complete restitution of fetal blood occurred in only $3 \mathrm{~h}$, demonstrating that the dynamic fetal fluid system can accurately regulate its blood volume. Therefore, it is unlikely that the mortality, which was as high as $67 \%$ (10 of 15 animals) within the first day after the experiment, is caused by fetal hemorrhage resulting from the experimental protocol. The dead fetuses did not develop anemia before death. This strengthens the idea of ongoing pump failure during severe asphyxia, leading to insufficient placental perfusion, prolonged hypoxia. and progressive decompensation of both the metabolic and cardiovascular equilibrium. Most animals did not recover and died within $1 \mathrm{~d}$. Of the five animals completely recovering from asphyxia and surviving longer than $1 \mathrm{~d}$, four were treated with flunarizine. With these low numbers, only speculations can be made on protective properties of flunarizine. It also remains questionable to what extent fetal brain damage has contributed to the high percentage of early fetal demise.

In summary, the present data show that flunarizine, given after a period of severe asphyxia of $1 \mathrm{~h}$ in preterm fetal lambs, does not influence rCBF in the immediate postasphyxic period and does not affect FHR, Pa, or Pv. Mortality after such a long period of asphyxia is high; the effect of flunarizine on survival remains to be elucidated.

It is concluded that a possible beneficial effect of flunarizine on the fetal brain after asphyxia cannot be ascribed to an altered $\mathrm{CBF}$, to its effect on systemic arterial or venous blood pressure. or to its influence on FHR.

\section{REFERENCES}

1. Espinoza MI, Parer JT 1991 Mechanisms of asphyxial brain damage, and possible pharmacologic interventions, in the fetus. Am J Obstet Gynecol 164:1582-1591

2. Vanhoutte PM. Paoletti R 1987 The WHO classification of calcium antagonists. Trends Pharmacol Sci 8:4-5

3. Silverstein FS. Buchanan K. Hudson C, Johnston MV 1986 Flunarizine limits hypoxia-ischemia induced morphologic injury in immature rat brain. Stroke 17:477-482

4. Gunn AJ, Mydlar T, Bennet L, Faull RLM, Gorter S, Cook C, Johnston BM. Gluckman PD 1989 The neuroprotective actions of a calcium channel antagonist, flunarizine, in the infant rat. Pediatr Res 25:573-576

5. Van Reempts J, Borgers M, Van Dael L, Van Eyndhoven J, Van de Ven M 1983 Protection with flunarizine against hypoxic-ischemic damage of the rat cerebral cortex. A quantitative morphologic assessment. Arch Int Pharmacodyn Ther 262:76-88

6. De Rijck M, Van Reempts J, Borgers M. Wauquier A. Janssen PAJ 1989 Photochemical stroke model: flunarizine prevents sensorimotor deficits after neocortical infarcts in rats. Stroke 20:1383-1390

7. Van Nueten JM, Van Beek J, Janssen PAJ 1978 Effect of flunarizine on calcium-induced responses of peripheral vascular smooth muscle. Arch int Pharmacodyn Ther 232:42-52

8. Steen PA. Newberg LA, Milde JH, Michenfelder JD 1983 Nimodipine improves cerebral blood flow and neurologic recovery after complete cerebral ischemia in the dog. J Cereb Blood Flow Metab 3:38-43

9. Peeters LLH, Sheldon RE, Jones MD, Makowski EL. Meschia G 1979 Blood flow to fetal organs as a function of arterial oxygen content. Am J Obstet Gynecol 135:637-646

10. Farber JL 1981 The role of calcium in cell death. Life Sci 29:1289-1295

11. Katz AM, Reuter H 1979 Cellular calcium and cardiac cell death. Am J Cardiol 44:188-190

12. Siesjö BK 1981 Cell damage in the brain: a speculative synthesis. J Cereb Blood Flow Metab 1:155-185

13. de Haan HH, de Haan J, Van Reempts JLH, Van Belle H, Hasaart THM 1993 The effect of adenosine transport inhibition on cardiovascular function and survival after severe asphyxia in fetal lambs. Pediatr Res 33:185-189

14. Rudolph AM, Heymann MA 1967 The circulation of the fetus in utero. Circ Res 21:163-184 
15. Todd PA, Benfield P 1989 Flunarizine. A reappraisal of its pharmacological properties and therapeutic use in neurological disorders. Drugs 38:481-499

16. Buckberg GD, Luck JC, Payne B, Hoffman JIE, Archie JP, Fixler DE 1971 Some sources of error in measuring regional blood flow with radioactive microspheres. J Appl Physiol 31:598-604

17. Van Nueten JM, Vanhoutte PM 1980 Improvement of tissue perfusion with inhibitors of calcium ion influx. Biochem Pharmacol 29:479-481

18. Newberg LA, Steen PA, Milde JH. Michenfelder JD 1984 Failure of flunarizine to improve cerebra! blood flow or neurologic recovery in a canine model of complete cerebral ischemia. Stroke 15:666-671

19. Borgers M, Van Reempts J 1989 Effects of $\mathrm{Ca}^{2+}$-entry blockers on ischemic brain. J Neurosurg Anesth 1:368-374

20. Akaike N, Kostyuk PG, Osipchuk YV 1989 Dihydropyridine-sensitive lowthreshold calcium channels in isolated rat hypothalamic neurones. J Physiol (Lond.) 412:181-195

21. Van Reempts J, Van Deuren B, Van de Ven M. Cornelissen F, Borgers M 1987 Flunarizine reduces cerebral infarct size after photochemically induced thrombosis in spontaneously hypertensive rats. Stroke 18:1113-1119

22. Rich KM, Hollowell JP 1990 Funarizine protects neurons from death after axotomy or NGF deprivation. Science 248:1419-1421

23. Szymonowicz W, Walker AM, Cussen L, Cannata J, Yu VYH 1988 Develop- mental changes in regional cerebral blood flow in fetal and newborn lambs Am J Physiol 254:H52-H58

24. Bocking AD, Gagnon R. White SE, Homan J, Milne KM, Richardson BS 1988 Circulatory responses to prolonged hypoxemia in fetal sheep. Am J Obstet Gynecol 159:1418-1424

25. Jones CT, Robinson RO 1975 Plasma catecholamines in foetal and adult sheep. J Physiol (Lond) 248:15-33

26. Gu W, Jones CT, Parer JT 1985 Metabolic and cardiovascular effects on fetal sheep of sustained reduction of uterine blood flow. J Physiol (Lond) 368:109129

27. Block BS, Schlafer DH, Wentworth RA, Kreitzer LA, Nathanielsz PW 1990 Intrauterine asphyxia and the breakdown of physiologic circulatory compensation in fetal sheep. Am J Obstet Gynecol 162:1325-1331

28. Yaffe H, Parer JT, Block BS, Llanos AJ 1987 Cardiorespiratory responses to graded reductions of uterine blood flow in the sheep fetus. J Dev Physiol $9: 325-336$

29. Richardson BS, Rurak D. Patrick JE, Homan J, Carmichael L 1989 Cerebra oxidative metabolism during sustained hypoxaemia in fetal sheep. J Dev Physiol 11:37-43

30. Brace RA, Cheung CY 1986 Fetal cardiovascular and endocrine responses to prolonged fetal hemorrhage. Am J Physiol 251:R417-R424 